\title{
ARTE E BELEZA NO POEMA PEDAGÓGICO DE ANTON MAKARENKO
}

José Rômulo Soares ${ }^{1}$

\section{RESUMO}

Arte e beleza no Poema Pedagógico, de Anton Makarenko aborda a experiência educacional de Anton Makarenko (1888-1939) na Colônia Gorki e na Comuna Dzerjinsky, realçando seu trabalho com a arte e com a estética das relações humanas no processo educacional. Toma como obra central, o clássico Poema Pedagógico, no qual o pedagogo ucraniano relata sua práxis educativa durante dezesseis anos de trabalho à frente das referidas instituições. Gerado por pesquisa em curso, o trabalho investigativo, objetiva: Conhecer a proposta educativa de Makarenko, salientando seu interesse pela arte; Compreender o papel da estética na práxis educativa de Makarenko; Elencar as contribuições de Makarenko para a educação atual, destacando sua práxis educativa relacionada à arte e à estética. De natureza bibliográfica, o caminho do pensamento na análise dos dados adota os princípios da dialética materialista histórica, tomando como categorias metodológicas: totalidade, contradição, e mediação. Como categorias de conteúdo, a investigação elege: arte, estética e práxis educativa. A exposição salienta a importância da arte e da estética para a formação humana escolar e a atualidade da herança makarenkiana para a práxis educativa hodierna.

Palavras-chaves: Arte. Beleza. Poema pedagógico. Makarenko. Educação.

\begin{abstract}
Art and beauty in The Pedagogical Poem by Anton Makarenko addresses the educational experience of Anton Makarenko (1888-1939) at Gorky Colony and Dzerjinsky Commune, highlighting his work with art and the aesthetics of human relations in the educational process. It takes as its central work the classic The Pedagogical Poem, in which the Ukrainian educator recounts his educational praxis for sixteen years of work leading those institutions. Generated by ongoing research, this investigative work aims to: know Makarenko's educational proposal, emphasizing his interest in art; understand the role of aesthetics in Makarenko's educational praxis; list Makarenko's contributions for the present education, highlighting its educational praxis related to art and aesthetics. Being this work a bibliographic research, the way of thinking in data analysis adopts the principles of historical materialist dialectic, taking as methodological categories: totality, contradiction and mediation. The research elects the following as content categories: art, aesthetics and educational praxis. The work highlights the importance of art and aesthetics in the human formation and education and the currentness of the makarenkian heritage for today's educational praxis.
\end{abstract}

Keywords: Art. Beauty. The pedagogical poem. Makarenko. Education.

\footnotetext{
${ }^{1}$ Doutor em Educação pela Universidade Federal do Ceará (2007) e Professor Adjunto da Universidade Estadual do Ceará, em particular, do Centro de Educação. E-mail: romulosoaresjr@ yahoo.com.br
} 


\section{INTRODUÇÃO}

Este texto aborda a práxis educativa do pedagogo ucraniano Anton Semionovich Makarenko (1888-1939) no contexto de sua clássica obra intitulada Poema Pedagógico (2005). Publicada originalmente em três tomos ${ }^{2}$, em 1933, 1934 e 1935, na extinta União das Repúblicas Socialistas Soviéticas - URSS, Poema Pedagógico alcançou repercussão mundial, influenciando a práxis educativa de significativo número de professores em diferentes partes do planeta.

No Poema Pedagógico, Makarenko narra sua experiência educacional na Colônia Gorki e na Comuna Dzerginsky, expondo as diferentes nuances da práxis educativa vivenciada junto às crianças, aos jovens, aos professores, como também a outros auxiliares das referidas instituições e às comunidades próximas à Colônia e à Comuna.

Dentre os diversos aspectos de relevo da pedagogia makarenkiana, analisamos os esforços do pedagogo ucraniano para valorizar a estética na formação das crianças e dos jovens sob sua responsabilidade, imprimindo neles o gosto pela beleza e pela criação artística. Considerando o quadro de dificuldades extremas encontrado pelo educador em debate, marcado pela carência generalizada, inclusive de víveres e de água de qualidade, chama a atenção do leitor do Poema Pedagógico, a dedicação de Makarenko a um tipo de formação que valoriza a sensibilidade estética no contexto da coletividade a qual se empenha para formar o novo homem, ou seja, o homem socialista.

$\mathrm{Na}$ análise da experiência estética de Makarenko, a investigação ${ }^{3}$ se filia à proposição vigostskiana, sustentadora da ideia de que "A arte é o social em nós, e, se o seu efeito se processou em um indivíduo isolado, isso não significa, de maneira nenhuma, que as suas raízes e essências sejam individuais”. (VIGOTSKI, 1999, p. 315).

O pensamento guia da investigação, fundada-se na Filosofia da Práxis, herdeira e difusora do ideário marxista e se apoia no materialismo histórico e dialético. Conforme Frigotto (1994), o enfoque da dialética materialista histórica, ancorado na Filosofia da Práxis, caracteriza-se por tratar o objeto de estudo no contexto da contraditória totalidade social, estabelecendo mediações complexas entre o universal, o particular e o singular. Para o

\footnotetext{
${ }^{2}$ Para análise da obra em relevo adotamos a versão brasileira publicada, em 2005 , num único volume pela Editora 34. Cf. referências.

${ }^{3} \mathrm{O}$ presente texto sintetiza resultados do relatório parcial da pesquisa do mesmo título realizada sob nossa coordenação, na Universidade Estadual do Ceará (UECE), com a participação de bolsistas de agências como FUNCAP e CNPq.
}

\begin{tabular}{|l|l|l|l|l|}
\hline Revita Dialectus & Ano 2 & n.7 & Setembro-Dezembro 2015 & p. $82-93$ \\
\hline
\end{tabular}


referido autor, esse processo crítico-reflexivo conduz o pesquisador à compreensão das leis que regem os fenômenos e a captar a realidade em seus nexos essenciais.

Decorrente do exposto, dois grupos de categorias conduzem nossas reflexões: primeiro, as categorias metodológicas, exatamente aquelas que realizam um corte transversal nas relações entre conteúdo, método e postura do pesquisador, quais sejam: totalidade, contradição, e mediação. Por totalidade, compreende-se a formação social examinada em suas características próprias, marcada pelas contradições e pela transformação constante. Por mediação, entende-se a forma de se estabelecer relações particulares, ou mesmo singulares, com a "totalidade concreta" (KOSIK, 1994), reforçando a perspectiva do todo nas relações particulares. Por sua vez, contradição diz respeito, mais diretamente, ao aspecto antagônico das relações sociais características das sociedades de classes.

Quanto às categorias de conteúdo, ou seja, as mais expressivas na temática da investigação elegem-se: Arte, estética, e práxis educativa. Arte significa o esforço humano criativo de expressão objetivada, pois

[...] o trabalho para um artista é um processo altamente consciente e racional, um processo ao fim do qual resulta a obra de arte como realidade dominada de modo algum - um estado de inspiração. (FISCHER, 2002, p. 14).

Por sua vez, estética exprime a natureza do belo, envolvendo a percepção, o julgamento, os sentimentos em relação à obra de arte. Estética diz respeito ao sublime, como também à técnica artística na criação da obra de arte. Refere-se à apreciação da beleza dos objetos criados pelos seres humanos e discute suas relações com a individualidade e com social.

Para Vázquez (2010), na abordagem marxista, o estético não pode ser separado do humanismo, porquanto Marx aliou o pleno desenvolvimento das potencialidades humanas a um tipo de sociedade que, ao retirar o capital de seu centro, sobrelevasse o humano. Para o filósofo mexicano-espanhol, "O artista é o homem que cria objetos segundo as leis da beleza, ou seja, transformando uma matéria a fim de imprimir nela uma forma e explorar, assim num objeto concreto-sensível - sua essência humana" (VÁZQUEZ, 2002, p. 79). O capitalismo, ao contrário, ressalta a atividade artística como "produtiva", pois a obra de arte aparece como uma mercadoria semelhante à outra qualquer. Nesse sentido, a atividade artística se prende às leis do mercado, comprometendo suas raízes com as leis da beleza.

Quanto à categoria práxis educativa, a exposição a toma como nuclear à sua abordagem, por trata-se de uma investigação na área educacional, no contexto de uma

\begin{tabular}{|l|l|l|l|l|}
\hline Govista Oialoctus & Ano 2 & n.7 & Setembro-Dezembro 2015 & p. 82 - 93 \\
\hline
\end{tabular}


experiência socioeducativa, no caso, a práxis educativa de Anton Makarenko, na Ucrânia, na primeira metade do século XX.

Nesse sentido, a categoria práxis educativa envolve desde concepções acerca do fenômeno educacional, até o trabalho efetivamente realizado em sala de aula ou em outros espaços educativos. Diz respeito também à política educacional, às relações sociais, à participação da comunidade da vida escolar, dentre outros aspectos. Na práxis educativa, registra-se a presença de uma série complexa de mediações que elucidam contradições internas e externas na tensão dialética das ricas relações da totalidade complexa da vida social.

No cotidiano escolar, a práxis educativa torna-se ato nas diferentes atividades pedagógicas realizadas pelos professores, coordenadores, diretores, ou outros membros da instituição escolar ou da sociedade. Na escola, o professor conduz mais diretamente a práxis educativa, especialmente na sala de aula, mas sempre ligado com a práxis educativa proposta no projeto pedagógico da escola, na política educacional de seu estado e de seu país, seja para afirmá-las ou negá-las.

\section{MAKARENKO EM CENA}

Recebendo influência do marxismo, Makarenko se serve da proposta de formação omnilateral para realizar sua tarefa formativa. Ao invés da formação limitada da antiga pedagogia tzarista, livresca e mnemônica, como também das tendências instrumentalizantes da nova pedagogia norte-americana, A Escola Nova, o pedagogo socialista executou uma pedagogia do desenvolvimento potencial da totalidade das capacidades humanas, incluindo aí o papel da sensibilidade criativa como fator essencial da transformação da realidade revolucionária. Deste modo, praticou uma pedagogia não somente do trabalho e da disciplina, mas um processo educativo do desenvolvimento de personalidades ricas de conhecimento prático e teórico da realidade, destacando os elementos constitutivos da arte, como: a literatura, a poesia, a banda de música, o teatro, o cinema, a dança. Ademais, o ambiente educativo na Colônia Gorki e na Comuna Dzerginsky sempre fora enfeitado de flores, estas, cultivadas em demasia na Colônia e na Comuna e desfrutada em suas cores e odores por todos os colonistas e comunardos.

Por outro lado, Makarenko enfatiza a importância das relações humanas mediadas pela estética naquilo que denominou de uma estética do comportamento. Essa envolve a própria

\begin{tabular}{|l|l|l|l|l|}
\hline Qevista Dialectus & Ano 2 & n.7 & Setembro-Dezembro 2015 & p. $82-93$ \\
\hline
\end{tabular}


forma do postar e do vestir, mas considera fundamental a maneira respeitosa de tratamento dos outros, especialmente das crianças. Na condição de Flores de la vida ${ }^{4}$, Makarenko reconhece a beleza da infância como momento ímpar de uma série de responsabilidades dos adultos sobre a formação da personalidade infantil, inclusive no desenvolvimento do bom gosto e da convivência com os objetos de arte. Longe da concepção romântica dos jardins da infância da pedagogia de inspiração rousseauniana, Makarenko previa um inevitável fracasso nas pedagogias movidas pelo sentimentalismo espontaneísta em uso, no seu tempo. Assim, advoga uma pedagogia diretiva tomando a coletividade, em seu sentido estético, ético e político, como fator primordial do desenvolvimento de seres humanos plenamente desenvolvidos e comprometidos com uma arte realista, consciente e revolucionária. Uma arte que mostrasse o belo não somente como fruição ou apreciação passiva, mas que, no quadro das relações sociais, compreendesse a alegria e a beleza de se construir uma inédita forma de vida: a vida socialista.

Preocupado com a educação de hábitos culturais, Makarenko realçou a importância de várias atividades educativas, dentre elas, as atividades lúdicas, com destaque para o jogo infantil, pois o mesmo “[...] proporciona a alegria da criação, do triunfo, ou do prazer estético da qualidade". (MAKARENKO, 1981, p. 48).

Conforme o pedagogo em estudo, todas as atividades educativas, inclusive as artísticas e as lúdicas, deviam seguir a organização consciente dos adultos, evitando o espontaneísmo corrente na educação da época e preparando a autogestão nas relações pedagógicas.

Para compreender a práxis pedagógica de Makarenko é necessário situar o autor e sua obra no tempo e no espaço. Nascido em 1888, no seio de uma família pobre da cidade de Belapolie, situada na província de Kharkov, na Ucrânia, Makarenko cresceu sob o império da dominação do tzarismo russo. Experimentou, portanto, privações econômicas e culturais, como eram comuns na vida dos filhos de operários à época. Semion Grigorievich, seu pai, trabalhava como ferroviário, recebendo salário ínfimo e enfrentando sérias dificuldades no sustento da família, conforme Luedemann (2002).

Neste contexto, assegura Luedemann, Makarenko recebeu uma educação escolar limitada, caracterizada pelo formalismo do método tradicional e pela imposição da cultura russa aos filhos dos trabalhadores.

\footnotetext{
${ }^{4}$ Referência a Flores de la vida (El libro de los padres) título de fantasia oferecido ao Livro dos pais, obra de Makarenko publicada na argentina, em 1957. O Livro dos pais recebeu publicação em dois tomos em 1937 e 1939, respectivamente.
}

\begin{tabular}{|l|l|l|l|l|}
\hline Q Rovista Dialectus & Ano 2 & n.7 & Setembro-Dezembro 2015 & p. $82-93$ \\
\hline
\end{tabular}


O currículo das escolas populares era incompleto e impossibilitava que os filhos dos trabalhadores prosseguissem seus estudos nos graus mais avançados do ginásio e do ensino superior. Deveriam ser cultos, mas nem tanto... somente à elite caberia uma formação completa e profunda para comandar a sociedade”. (LUEDEMANN, 2002, p. 52).

No decorrer dos estudos, informa Luedemann, Makarenko licenciou-se para ensinar na educação primária, aos 17 anos de vida, licenciando-se em pedagogia, pelo Instituto pedagógico de Poltava, aos 29 anos de idade. A referida formação, segundo Luedemann, habilitava ainda para o cargo de diretor escolar. Por outro lado, sensível aos problemas de sua época, Makarenko obteve expressivo conhecimento da realidade devido ao seu autodidatismo. Ironicamente, a formação precária da escola ucraniana não o impediria de se tornar “[...] o maior pedagogo russo [...] (CAMBI, 1999, p. 558) do século XX. Segundo Luedemann, os textos revolucionários de Gorki influenciaram sobremaneira a formação política de Makarenko. Cedo, Makarenko aprendeu a questionar a vida de pobreza do povo ucraniano e a compreender que essa vida poderia abarcar inúmeras belezas. Com Gorki, Makarenko aprendeu que "O escritor é o arauto de seu país e de sua classe, é seu ouvido, seus olhos e seu coração; é a voz de sua época". (GORKI, 1984, p. 33). Deste ensinamento, Makarenko eludiu que o pedagogo também poderia ser os olhos, os ouvidos e o coração de uma juventude despedaçada pelos horrores das guerras. Entre 1911 e 1914, assevera Luedemann, Makarenko exerceu o cargo de diretor da escola Primária das Oficinas Ferroviárias, em Doliskaia, onde aprimorou sua práxis pedagógica, experimentando novas experiências educativas em confronto com a pedagogia corrente. Traço marcante dessa experiência se mostra na ampliação das capacidades culturais da Instituição, revelando o compromisso precoce do pedagogo com a arte e a beleza na educação. Seu encontro mais direto com a referida juventude se daria ainda em 1920, na antiga fazenda de correção para jovens infratores, mais tarde denominada Colônia Gorki. Segundo o pedagogo em estudo,

Antes da revolução, existia aqui uma colônia de menores delinquentes. Em 1917, ela se dispersou, deixando atrás de si poucos vestígios pedagógicos. A julgar por esses vestígios, preservados em surrados livros-diários, os diretores pedagógicos da colônia eram velhos militares, ao que parece, oficiais de baixa patente reformados, cujas obrigações consistiam em vigiar todos os passos de cada um de seus educandos, tanto no trabalho como nas horas de recreio, e à noite dormir no aposento contíguo. Pelo relato dos camponeses vizinhos podia-se deduzir que a pedagogia desses "tios" não primava pela complexidade. A sua expressão exterior se limitava a um instrumento da simplicidade de um porrete. (MAKARENKO, 2005, p. 14). 
Coube a Makarenko realizar a hercúlea tarefa de humanizar as relações socioeducativas na Colônia, organizando-a na forma de uma coletividade e valorizando os potenciais das crianças e dos jovens sob sua responsabilidade. Para executar esta empreitada, Makarenko enfrentou diversas carências materiais e as intempéries da natureza, especialmente o frio intenso. Na Colônia, lutou contra os velhos hábitos: individualismo, preguiça, roubos, violência contra os mais frágeis, desleixo, dentre outros aspectos negativos. Externamente, o pedagogo enfrentou os diretores do Departamento de Instrução Pública que não compreendiam seu trabalho na Colônia e nem colaboravam a contento para a efetivação do mesmo. De acordo com Heller (2004), as relações de Makarenko com o sistema administrativo soviético foi de constante conflito, conquanto o pedagogo apoiasse a revolução.

Quanto à vida social na Colônia Gorki, Heller sustenta: Trata-se de uma organização tão Heterogênea, tão polissêmica das possibilidades ativas da coletividade que cada um dos membros pode desenvolver suas capacidades naturais. (HELLER, 2004, p. 82). Dentre as potencialidades naturais dos indivíduos, Makarenko dedicou supremo valor àquelas relacionadas às potencialidades artísticas, ao convívio com a beleza e com a alegria de viver. Decorrente dessa concepção, “[...] Para Makarenko, a arte, o teatro, a música e as matérias convencionais fazem parte da formação global do homem. (MAIA, 2010, p. 33).

Se o capitalismo é incompatível com a verdadeira arte, como afirma Vásquez (2011), o socialismo deveria assumi-la como elemento fundamental na formação dos novos seres humanos construtores da nova sociedade. Conforme Heller (2004), a construção de uma comunidade de valor axiológico positivo, como a Colônia Gorki, somente se realizou devido às possibilidades que o socialismo engendra para a existência de comunidades de tal ordem de valor. Nesse tipo de comunidade “[...] os sujeitos encontram possibilidades concretas de desenvolvimento de suas individualidades na comunidade, superando assim o conflito entre interesses individuais e gerais". (SOARES, 2012, p. 51).

Para Makarenko, não restava dúvidas relativamente ao potencial criativo e transformador da arte e da construção coletiva da beleza na transformação da vida coletiva, sob o socialismo. Para isto, Makarenko lutou para "[...] exagerar o bom [...] aniquilar as vilanias da vida, a mesquinharia chata e cúpida”. (SODRÉ, 1968, p. 81). Nesse sentido, o trabalho, antes enfadonho e penoso, assume perspectiva oposta, pois coletivo e prazeroso, atende às necessidades humanas e apresenta sentido estético na beleza e sua realização. $\mathrm{O}$ plantio de alimentos ou de flores, a colheita, o cuidado com os animais, o alimentar-se com o

\begin{tabular}{|l|l|l|l|l|}
\hline Govista Oialectus & Ano 2 & n.7 & Setembro-Dezembro 2015 & p. $82-93$ \\
\hline
\end{tabular}


produto do trabalho, tudo envolvia posturas estéticas, criatividade e alegria, ao mesmo tempo em que elevava a autoestima das crianças e dos jovens colonistas. Antes, meninos de rua, assaltantes, delinquentes, agora produtores de suas vidas. Outrora considerados incorrigíveis, agora artistas, músicos a proporcionar alegrias para a coletividade. Participando de gruposclubes ou círculos: dramáticos, de literatura, de coro, de música, de pintura, de dança, de radioamadores, de trabalhos manuais, de línguas estrangeiras, dentre outros, estes indivíduos encontravam reais possibilidades de desenvolvimento integral de suas potencialidades humanas, expressando capacidades artísticas e tornando-se autores da beleza objetivada nos diversos materiais por eles produzidos. Desse modo, "Portanto, o ser humano aprende a se tornar humano, e isso só é possível ao se apropriar do patrimônio de objetivações humanas. (FONTE, 2010, p, 136).

Fundamentado em Marx, Makarenko compreende que a divisão do trabalho na sociedade, divide os seres humanos em artistas e não-artistas. Entendia, sobretudo, como Marx havia expressado em A ideologia alemã, que o desenvolvimento de apenas uma esfera da vida, limita os seres humanos a profissões e à especializações, muitas vezes, estéreis, pois, "Numa sociedade comunista não haverá pintores, mas, no máximo, homens que, entre outras coisas, também se ocupam com a pintura". (MARX; ENGELS, 2010, p. 168). Este ensinamento tornou-se caro ao pedagogo ucraniano na sua tarefa educativa, primordialmente, uma tarefa de expressão da beleza da vida nas relações coletivas dos novos seres humanos em construção, no socialismo.

\section{ATUALIDADE DE MAKARENKO}

A perspectiva educacional de Makarenko apresenta atualidade diante das contribuições desse pedagogo a questões essenciais à práxis educativa, como: as relações entre prática e teoria; o trabalho educativo numa concepção coletivista, o planejamento e a disciplina, a formação integral dos educandos, a autonomia dos educandos, dentre outros aspectos de importância histórica para o campo educacional.

Em publicação acerca do pedagogo ucraniano, Filonov explica:

[...] Para Makarenko, o tempo de educar contempla todos os tempos sociais, inclusive da cultura, do lazer, do descanso, até mesmo quando as crianças estão se preparando para dormir. A educação da coletividade, de todas as crianças, em suas diferentes personalidades, deve tomar tanto os diferentes momentos de suas vidas, os espaços diferenciados, quanto o desenrolar do 
processo, não se deixando enganar pela análise de um ou de outro episódio isolado da ação dos educandos. (F I L O N O V , 2010, p. 34 ).

Na pesquisa em curso, salientamos o trabalho pedagógico de Makarenko no que se refere à formação estética dos educandos, ou seja, sua dedicação ao convívio com a criação artística e com os elementos da beleza da vida.

A importância em abordar o aludido tema se dá diante das atuais limitações na formação docente quanto às relações entre educação e estética, havendo, portanto, um vácuo na formação destes profissionais. Desta feita, a investigação se propõe a contribuir com este assunto de sumo relevo para a formação de educadores e educandos, hoje, carentes dos conhecimentos acerca da formação estética e artística. A necessidade da arte, como exposta por Fischer (2002), anima o estudo acerca da temática, no intento de relacionar a estética à práxis educativa cotidiana de educadores e educandos.

Os passos iniciais dessa investigação foram perquiridos em pesquisa em andamento intitulada: Formação Humana Escolar em Anton Makarenko: práxis, coletividade e estética. A referida pesquisa, objetiva: Compreender a proposta de formação humana escolar de Anton Makarenko; Analisar as categorias práxis, coletividade e estética no contexto da obra de Anton Makarenko; Elencar as contribuições das ideias de Anton Makarenko para a formação humana, observando a atualidade de seu pensamento educacional.

Por se tratar de tema relacionado ao cultivo da sensibilidade humana, a pesquisa poderá contribuir com debates sobre o desenvolvimento de potencialidades ora deixadas à margem no contexto escolar. Ao destacar o trabalho com gosto pela beleza, novas possibilidades poderão surgir através da criação artística, envolvendo a expressão corporal, como também de sentimentos. A arte como expressão da vida real de seres humanos em relações complexas e contraditórias, surge assim, como elo de conscientização a respeito das grandes questões da existência, como também como inspiradora da ação de transformar a realidade, de melhorar a vida, de torna-la digna de ser vivida. Diante das expressivas dificuldades do trabalho pedagógico nos tempos atuais, as crianças e os jovens necessitam, com e urgência, se relacionarem com o conhecimento estético da criação artística, como forma de despertá-las para a alegria da vida e para as esperanças de um presente e um futuro melhores. Pensamos que o trabalho com o conhecimento estético pode contribuir sobremaneira com esta tarefa.

\section{CONSIDERAÇÕES FINAIS}

\begin{tabular}{|l|l|l|l|l|}
\hline Qenista Dialectus & Ano 2 & n.7 & Setembro-Dezembro 2015 & p. $82-93$ \\
\hline
\end{tabular}


Anton Makarenko trabalhou trinta e dois anos como pedagogo, na Ucrânia, dos quais dedicou dezesseis anos à práxis educativa na Colônia Gorki e na Comuna Dzerjinsky. Durante esse período aplicou um método pedagógico próprio, no qual considerou as necessidades da sociedade quanto à educação e as necessidades dos indivíduos e do coletivo, quanto à sociedade.

Seu método pedagógico prima pela formação integral dos educandos, na qual a pedagogia ancora os princípios de uma educação rica, elevando as potencialidades humanas, mormente seu aspecto criativo e transformador.

Segundo Manacorda, a pedagogia de Makarenko apresenta “[...] perspectivas de vida e de alegria, 'da alegria do amanhã', como ele diz”. (MANACORDA, 1996, p. 316).

Para Makarenko, o papel da pedagogia como ciência da educação, seria justamente o de orientar o desenvolvimento da formação humana no sentido da formação integral, visto que, "Na educação soviética, não há diferenças fundamentais entre o trabalho físico e o trabalho intelectual". (MAKARENKO, 1981, p. 60) e o sentido estético da educação surge como elemento fundamental de integração dos seres humanos na construção da nova sociedade socialista.

Dessa forma, Makarenko (1986, p. 141) se propõe a "[...] embelezar a coletividade [...]”. Para o pedagogo em análise, o belo deveria estar presente no vestuário; nos objetos de trabalho; nos ambientes de habitação, trabalho e lazer; mas também no comportamento dos indivíduos.

Segundo Makarenko, a estética do comportamento deveria atingir uma forma que oferecesse indícios de uma cultura mais elevada. Dessa feita, os indivíduos deveriam ser esteticamente expressivos na linguagem, no vestir, nos relacionamentos com os outros.

Consciente da importância da formação estética, Makarenko criou várias oportunidades de desenvolvimento e potencialização das capacidades artísticas de seus educandos, valorizando o teatro, a música, a literatura, a dança, a pintura, dentre outras atividades.

No Poema Pedagógico, Makarenko apresenta uma proposta de organização da vida individual e coletiva, na qual os elementos da estética recebem atenção especial. Para o pedagogo em análise, a estética representa não somente a fruição da beleza, mas surge como um elemento próprio das necessidades humanas, contribuindo sobremaneira para a elevação das crianças e dos jovens sob sua responsabilidade, a um grau de humanização efetiva.

\begin{tabular}{|l|l|l|l|l|}
\hline Q & Ano 2 & n.7 & Setembro-Dezembro 2015 & p. $82-93$ \\
\hline
\end{tabular}




\section{REFERÊNCIAS}

CAMBI, Franco. História da pedagogia. Tradução: Álvaro Lorencini. São Paulo: Fundação Editora da UNESP, 1999.

DUARTE, Newton. Arte e formação humana em Vigotski e Lukács. In: DUARTE, Newton, FONTE, Sandra Soares Della (Orgs). Arte, conhecimento e paixão na formação humana. Sete ensaios de pedagogia histórico-crítica. Campinas, SP: Autores Associados.

FILONOV, G. N.; BAUER, Carlos; BUFFA, Ester (Orgs). Anton Makarenko. Recide, PE, Fundação Joaquim Nabuco, Editora Massangana, 2010. (Coleção Educadores). Disponível em: < http://pt.scribd.com/doc/62451236/Makarenko-MEC-Unesco> Acesso: 10/04/2013.

FONTE, Sandra Soares Della. Amor e paixão como facetas da educação: a relação entre escola e apropriação do saber. In: DUARTE, Newton, FONTE, Sandra Soares Della (Orgs). Arte, conhecimento e paixão na formação humana. Sete ensaios de pedagogia históricocrítica. Campinas, SP: Autores Associados.

FISCHER, Ernest. A necessidade da arte. Tradução: Leandro Konder. Rio de Janeiro: Guanabara Koogan, 2002.

HELLER, Agnes. O cotidiano e a história. Tradução: Carlos Nelson Coutinho e Leandro Konder. São Paulo: paz e Terra, 2004.

KONDER, Leandro. Os marxistas e a arte. São Paulo: Expressão popular, 2013.

LUEDEMANN, Cecília da Siveira. Anton Makarenko, Vida e obra - a pedagogia da revolução. São Paulo: Expressão Popular, 2002.

MAIA, Lucíola Andrade \& PINHEIRO, Carísia Maia. Mestres da Educação Socialista: Anton Makarenko e Florestan Fernandes. Fortaleza: Centro Cultural do Benfica, 2010.

MAKARENKO, Anton. Conferências Sobre Educação Infantil. .São Paulo: Editora Moraes, 1981.

. Problemas da Educação Escolar. Moscou: Edições Progresso, 1986.

Poema Pedagógico. Tradução: Tatiana Belisky. São Paulo: Editora 34, 2005.

Livro dos Pais I. Tradução: M. Rodrigues Martins. Lisboa, s/d.

Livro dos Pais II. Tradução: M. Rodrigues Martins. Lisboa, 1981

MANACORDA, Mário Alighiero. História da educação. Da antiguidade aos nossos dias. São Paulo: Cortez, 1996.

\begin{tabular}{|c|c|c|c|c|}
\hline Rovista Dialectus & Ano 2 & n.7 & Setembro - Dezembro 2015 & p. $82-93$ \\
\hline
\end{tabular}


MARX, Karl; ENGELS, Freiderich. Cultura, arte e literatura. Textos escolhidos.Tradução: José Paulo Neto e José Makoto Cavalcanti Yoshida. São Paulo: Expressão Popular, 2010.

MÉSZÁROS, István. Para além do capital. São Paulo: Boitempo; Campinas: Editora da UNICAMP, 2002

MINAYO, Cecília de Souza. O desafio do conhecimento. Pesquisa qualitativa em saúde. São Paulo: Hucitec; Rio de Janeiro: Abrasco, 1999.

MORAES, Célia Marcondes de. Iluminismo às avessas. Produção de conhecimento e políticas de formação docente. São Paulo: DP\&A, 2003.

SOARES, Rômulo. Educação e indivíduo pragmático na crise do capitalismo contemporâneo. In: Indivíduo e educação na crise do capitalismo. Fortaleza: Edições UFC, 2012.

SODRÉ, Nelson Werneck. Fundamentos da estética marxista. Rio de Janeiro: Civilização Brasileira, 1968.

VÁZQUEZ, Adolfo Sánchez. Filosofia e circunstâncias. Rio de Janeiro: Civilização Brasileira, 2002.

VÁZQUEZ, Adolfo Sánchez. As ideias estéticas de Marx. Tradução: Carlos Nelson Coutinho. São Paulo: Expressão Popular, 2010.

VÁZQUEZ, Adolfo Sánchez. Filosofia da práxis. Tradução: Luis Fernando Cardoso. Rio de Janeiro: Civilização Brasileira, 1977.

VIGOTSKI, L. S. Psicologia da arte. Tradução: Paulo Bezerra. São Paulo: Martins Fontes, 1999. 